\title{
Travelling Models \\ Introducing an Analytical Concept to Globalisation Studies
}

\author{
Andrea Behrends, Sung-Joon Park and Richard Rottenburg
}

\section{Travelling Models as an Analytical Concept}

The chapters of this book each examine how travelling models shape global processes of change in the field of conflict management. Two of the principal questions addressed in the chapters are the following: How is change in one place related to developments in other places? And, why are certain issues that are important in one place taken up in other places, while others are not? The authors examine how travelling models enact changes in conflict situations in unexpected ways. They look at what happens when a model has been put into practice at a conflict site, and they pay attention to the forms of (re-)ordering resulting from this process. In the first part of this introductory chapter we elaborate travelling models as an analytical concept, and in a second part we look at how such models work in conflict resolution and management.

We start from the concept of travelling models as developed by Richard Rottenburg in his book Far-fetched Facts (2002; translated and revised 2009a) for the analysis of processes of change that occur on a global scale. In his monograph on the role of technologies of inscription in the making of objectivity within the global organisational field of development, however, the concept is more used than elaborated and explained. We will therefore consider some of the scholarly debates and theoretical discussions that evolved in the 10 years since the publication of Far-fetched Facts to sharpen our argument and clarify its contribution to the field. ${ }^{1}$

Following Richard Rottenburg, a model can be understood essentially as an analytical representation of particular aspects of reality created as an apparatus or protocol for interventions in order to shape this reality for certain

1 The ideas that went into this text emerged from innumerable discussions within the Travelling Models Group (http://www.scm.uni-halle.de/gsscm/forschung/travelling_models/). Discussions within the LOST-Group also contributed significantly where previous versions of this Introduction were debated and where much of the ongoing research centres on similar issues (http://www.ethnologie.uni-halle.de/lost/). 
purposes. Models - and the ideas about reality inscribed into them - always come objectified and combined with material technologies to put them into practice and to transfer them as blueprints to new sites. The notion of the model implies that the travelling apparatus is already circulated widely otherwise it would not have the status of a model.

Models, however, do not diffuse by themselves and they cannot be transferred without being translated. Translating models means that they travel by being conveyed, carried, picked up, called for and interpreted by various actors or - as we will call them - mediators. The working of models also presupposes techniques understood as "skilled practices" (Haraway 1991, 194) in how to deal with the standardised blueprint in concrete circumstances that are always unique. These techniques consist of embodied knowledge that does not travel with the objectified model but needs to be re-invented at the new sites through experimental practice and experience. Similarly, the working of models presupposes whole sets of surrounding institutions with their stabilising forms and conventions that, again, do not travel with the objectified model.

Our approach, which is constructed around the analytical concept of the travelling model, is certainly inspired by Science and Technology Studies. This is particularly important for our basic understanding of the way epistemic orders and social orders - or rather, practices of knowing and practices of ordering the world - are inseparably interconnected and mediated by social and material technologies (Jasanoff 2004).

When comparing the analytic concept of travelling models to other possible concepts, the first striking observation is that its main theoretical rival is the concept of rationalisation. Rationalisation in the Weberian tradition implies that models of ordering social relations which increase rationality will always beat other models. The main point in our approach is that it does not carry any such heavy presupposition. It has, after applying Occam's razor, the advantage of needing only a minimum of presuppositions. A travelling model neither instigates the excitement nor the superiority of enhanced rationality. Most importantly, it is not assumed that a model travels because it is superior, i.e. results in higher rationality, or in any sense better than what is available at a site. Furthermore, rationalities cannot travel as such, because they are immaterial and abstract and lack the robust form to be transportable. At the same time they are embedded in particular epistemic communities as well as in institutional and material networks and are inseparable parts of these multilayered networks, which generated them. But - and this is the crucial point the only transportable thing that can travel is the objectified model that depicts an aspect of a certain social order with its rationality. This aspect, however, belongs to the multi-layered order that stays behind. 
In this view, before something becomes a model worth imitating, it is an element of an ontological, epistemic, normative or material order. Only by being distinguished and disconnected from its setting this element becomes a token of this setting. A token is a thing that works like an established symbol of something, but also as replacement and evidence of the order for which it stands. $^{2}$

Once a token - defined in this way - travels, it is de-territorialised from its original setting and re-territorialised in new settings and problem-spaces (see also Cooper 2005). For this to happen, anything related to this move changes. While the token enters into a new setting with a different ontological and epistemic background, a different institutional set-up and technological infrastructure, it needs to adapt to these new circumstances in order to connect to them. So the first thing that changes is the travelling token. It also changes in the sense that it is only the very process of being picked up that makes the token into a model. The more often this happens, the higher the chances of becoming a stable, black-boxed model that travels easily. This, moreover, has retroactive effects on the context from whence the token emerged, which potentially becomes a site noted for its power to export models and for inviting imitation by those who want to follow what is perceived to be a route to success. The third element that is transformed is the site to which the token is connected in order to work. Individual and collective actors reformulate the problem addressed by the model and thereby create new interpretations of their reality. A token has thus been transferred from one site to another, and starts to act in its new site, thereby turning it into something different from what it was before. There are however cases where travelling elements become adapted and connected without this having a great impact on the new sites into which they are integrated. In these cases it seems appropriate to speak of appropriation or vernacularisation. One might also say that one extreme form of adaption is when the token becomes appropriated and all the rest remains unchanged, while the opposite extreme form is when the receiving context changes while the token remains more or less the same. We argue that most cases are somewhere in the middle of these two unlikely extremes; in the middle where everything is being transformed. It is how exactly this transformation occurs that we are interested in, and for this microscopic examination we employ the concept of translation (Kaufmann and Rottenburg 2012).

Looking at processes of transfer, adaptation and appropriation as translations allows us to follow travelling elements on their journeys between

2 A token can, for instance, be a device such as a coin bought for use with machines or for other payments where money is not handled. See also Latour (1986) for a similar use of 'token'. 
different sites - both in a fine-grained minute fashion or by tracing larger, more encompassing, trajectories. Opening the 'black box' of transfer means not only to observe how ideas assembled in one site connect with meanings and practices in another, but also to focus on the many steps of the trajectory when an idea is de-territorialised and re-territorialised in any given site or problemspace. In this perspective, the sending and the receiving sites are considered to be of equal importance for the translation of the token that makes it travel. Conceiving transfers as translations avoids juxtaposing autochthonous and imported social and cultural forms. Instead, translation draws attention to the fact that most social and cultural transformations are firmly entangled with transformations that take place elsewhere.

The translation of a travelling element that thereby becomes a model is, in other words, inherent to its deployment. It cannot be deployed in order to enter new connections without being translated. A model as apparatus is itself a technology of ordering that comes with a protocol for its own handling. Yet the interpretation of a protocol depends on a multitude of implicit assumptions, tacit knowledge and surrounding technological and institutional networks that were all left 'at home'. In the new context this leads to a frequently amazing interpretative flexibility. The practice that follows the deployment of a model is never sufficiently explained by reference to the transferred apparatus and the protocol accompanying it. This is the tipping point between transfer and translation.

\section{Rationalities do not Travel, Models do. An Example: the Chadian Oil Model}

To illustrate our approach, we look briefly at one example, that of oil extraction in the African country of Chad. With its war-torn past and present, investors in Chad's oil industry had long questioned the potential of oil production in that country. Mainly this was because they feared the risks insecurity posed to their investments, but there was also an awareness that oil revenues had in other places been a trigger for armed rebellion, the prolongation of dictatorships, and ultimately seemed to hinder democratic state structures (for 'resource curse' theories, see Auty 1993). In the case of Chad, efforts were made to avoid this set of problems by introducing a wealth-sharing model aimed at an equitable revenue distribution. There has been much debate over this model and input from a broad range of actors, principally economists and lawyers of the World Bank, but also Chadian civil-society groups and international nongovernmental organisations (NGOS) working in the legal and resource-related sector (Guyer 2002; Pegg 2005, 2009). When the model was introduced to Chad, it came with a large package of measures, but the main element was the need 
for Chad to pass binding legislation (which, according to actor-network theory might be called an 'actant'; see Latour 2005). This legislation would regulate how oil revenues were to be invested - in public infrastructure, education and health, and as a reserve fund for future generations (Norway's handling of oil revenues strongly influenced the model; see Alt 1987). All these measures were supposed to avoid the so-called resource curse that had plagued Nigeria, Angola, Sudan and many other oil-producing countries.

What has happened to the model? The Chadian government accepted the model's inherent suggestions and passed the legislation required. Following this, the path for investment seemed open, oil production started and revenues began to flow in. However, the Chadian government used part of the oil revenue to purchase arms and strengthen the army, which was explicitly not part of the model's package. Moreover, the president single-handedly amended the constitution to extend his tenure beyond two terms. Growing internal dissent prompted the president to raid Chad's Future Generations Fund to buy more weapons (Ross 2003; Reyna 2009; Behrends 2008). When the World Bank complained, the Chadian government shut down oil production, paid back the World Bank loan and looked for other investors. The World Bank finally withdrew from oil-related operations in Chad. The oil companies, however, remained and oil production continued. How then can we make sense of this case, which would normally be treated as one more example of the failure of development practice?

We would argue that the answer lies in part in the way the model had been re-territorialised in a different setting. In this setting - that is in Chadian government circles - the development of infrastructure, education or health care was of lesser importance than the government's security. The Chadian president knew he could only remain in power if he significantly increased his security apparatus. The World Bank's rationality, which rhetorically came as a package to promote economic development in Chad, was based on the rule of law being a universally binding institution. This rationality with respect to understanding the model's inherent technologies - that legislation would be binding and determine all further use of oil revenues - remained, so to say, in Washington. Once in Chad, the model was confronted with another rationality, that of ever-imminent rebellion and violence. In this institutional setting, the rule of law has another significance, and therefore the model came to be used in ways other than intended.

Employing the travelling model concept offers fresh outlooks on such events. Beyond the explanation of how a model has been assembled and disassembled in a new situation, the concept takes account of the simultaneity of events, of different sites or situations and thus wider linkages and connections. 
It can cover a wide range of factors and at the same time concentrate on single actors, for instance those who conceptualise a model, those who circulate it, those who translate it or those who make use of it. All these actors translate the model, make it their own and convey it in their own way. Thereby, the model eventually changes. As Hoinathy and Behrends show (in this volume) the Chadian oil model is still a major reference point for non-governmental and civil-society organisations in southern Chad (see also Hoinathy 2008, 2012). And it travelled further afield, though not in the exact same form. In São Tomé and Príncipe - amongst other places - it was amended to take into account the events in Chad in an attempt to apply 'lessons learnt', as Weszkalnys shows in several contributions (Weszkalnys 2008, 2009).

\section{Travelling Models and Contemporary Alternatives}

In the section that follows, we explore further the concept of travelling models by comparing it to other, similar concepts and approaches. We begin by clarifying how the study of models contributes to theoretical debates that revolve around the term globalisation and its multiple modifications.

The travelling models concept provides a fruitful entry point to methodological choices that revolve around the relationship between theoretical concepts and empirical observations. To paraphrase Callon and Latour (1981) - to what extent can we explain microstructures by 'larger' macrostructures referred to by theoretical constructs such as 'globalisation'? What kind of generalisations can be inferred from a series of microstructure-level observations? Or, should one instead treat these structures as having the same dimensions? Of course, any scientific discipline and scholarly position addressing concepts such as globalisation - or, more recently again, neoliberalism - needs to consider such methodological questions. Here, the use of travelling models is pertinent, as models in most scientific disciplines reflect the relationship between empirical observations and theoretical generalisations. However, as models play a minor role in the broader field of social anthropology, we will begin with a brief exploration of how the notion of 'model' is understood in this book, and in so doing we elaborate travelling models as an analytical instrument in its own right. By presenting our understanding of models, we, of course, acknowledge the fact that models are always connected to the ontological assumptions and the epistemic background of the research in which they come to be applied.

One of Clifford Geertz's central theses in "Religion as Cultural System" suggests that models can be distinguished as 'models of' and 'models for' in the 
analysis of symbolic systems such as religion. According to Geertz, a theory becomes a model of 'reality' through a series of "manipulations of symbolic structures", which "render the reality apprehensible" (Geertz 1973, 93). In contrast, theories are considered as models for reality when models provide guidance on how 'physical relationships' are organised. For Geertz this distinction between 'model of' and 'model for' was crucial to describe cultural systems as models of and for collective practices. That is, models, such as cultural systems, are "patterned processes [and] structure in an alternative medium", which Geertz considered to be distinctive to human culture (ibid.). Geertz's contribution - now almost four decades old - proposed an understanding of models as an analytic tool to capture practices of signification, which give reality an objective form "both by shaping themselves to it and by shaping it to themselves" (ibid.).

While Geertz was using the notion of 'models for', the work of scholars in philosophy of science and Science and Technology Studies (STS) on models as a technology has complicated the understanding of theoretical concepts and empirical observations. Scholars in STS in particular have paid great attention to models as technologies in the production of scientific knowledge, which require enormous social and political power to count as an objective representation of reality. In the following section we summarise some of the results of these debates by drawing on a distinction provided by Kalthoff (2008) which helps us to articulate more closely our use of the travelling models concept.

Kalthoff suggests that the relationship between theory and empirical observations takes three pathways. First, he regards theories as models to direct empirical observations; second, he sees theories as categories grounded in empirical research; and third, he distinguishes theorising as an observable social process $(2008,12)$. Emphasising the analogy between first and third, the third perspective - to regard theorising as observable social processes - closely relates to travelling models as it describes what travelling models are: observable social processes. Lifting this kind of approach into the domain of empirical research has marked a key moment in social science. Since the Writing Culture debate, anthropological research in particular has produced a wave of reflexive and deconstructive accounts of 'doing ethnography', which, like some other modes of scientific knowledge production, is regarded as a social process (Clifford and Marcus 1986). At the same time, other disciplines such as Science and Technology Studies and organisational studies discovered how the ethnographic method can assist in situating or positioning socially scientific knowledge production, withoutdeconstructing ethnographyor otherrepresentational practices altogether (Haraway 1991). In formulating the concept of travelling models we have certainly been influenced by these and other scholarly debates, 
which, for example, broach the issue of how formal models crucially interfere in domains such as law, organisation, development, and also in science itself (Drori, Meyer, and Hwang 2006). We have come to regard the travel of formalised models as socially mediated processes. As we will outline in more detail below, these are processes which can be elucidated by analysing how new relations between a variety of elements are constructed, including human actors and non-human actors, thus producing ever new arrangements of social order (Callon and Latour 1981).

The second of Kalthoff's perspectives on theory - theories drawing on empirical observations - evokes the notions of 'middle-range theories' (Merton 1968) and of 'grounded theory' (Glaser and Strauss 1967). Instead of finding theory through abstraction, theory is understood here to define observable empirical objects, which, if comparatively applied to similar cases, yield substantial theoretical insights. In relation to this perspective, travelling models constitute an empirical field of comparative study (Czarniawska and Joerges 1996; Meyer, Drori, and Hwang 2006). In this respect the approach goes beyond the analysis that generally characterises Science and Technology Studies, which focuses in detail on the social constructions of scientific knowledge principally in one particular place without comparison with other places. Travelling models figure most prominently in various and mutually dependent global translations of law, organisation, science and technology around the world.

To place emphasis on the process of a model's travel as the main empirical object also moves us beyond the frequent distinction between universal global forms and local phenomena. This also applies to other dichotomies, such as modern and traditional, and legal and illegal, and which, as is by now widely accepted, are no longer helpful in the production of anthropological knowledge. Rather, it is the emergence of such conceptual dichotomies in particular theoretical contexts that comes to be of interest in the sense of Merton's notion of middle-range theories. Looking at travelling models suggests we follow the model to different places and analyse how it creates distinctiveness in relation to other places, precisely by evoking notions of the global or the local, modern and traditional, rational and irrational.

Finally - relating to Kalthoff's first notion of theories as models to direct empirical observations - the research concept of travelling models serves a very pragmatic purpose. Much of empirical research is confronted with a diversity of social phenomena, practices and problems in various and overlapping fields such as development aid and military intervention, big business and health infrastructure, and political process and legal amendments, which are temporally and spatially specific. Yet, these observations, which are necessarily localised in time and space, are interconnected with other observations 
at different places and times. It would be misleading to capture these interconnections only by tracing connections for example from the local to the global or vice versa. Instead, an analysis is required that looks at social mechanisms that are enacted to establish relations between multiple actors (Callon and Latour 1981). In this respect, the travelling models concept proposes to emphasise how things and ideas move from one place to the other, which suspends the contradiction between local specificities and global abstractions. We suggest instead that local specifics and global trends become visible exactly at the point where human actors, models, and technologies are enrolled into new networks to engage a particular problem. Thus what is global and what is local turns out to be dynamic - emerging from processes where distant actors are connected by dealing with a particular problem.

Most of the contemporary problems we study - whether involving conflict, human rights, or natural and social orders and disorders - deserve an anthropological understanding. We agree with Eriksen who argued early in the 199os that anthropologists needed to develop a scientific understanding of global problems - an understanding that would save the comparative discipline "from the important, but ultimately irresponsible criticisms of postmodernist deconstruction" (Eriksen 1991, 1). In this chapter, we thus examine the extent to which travelling models constitute new ways of thinking about the relationships between globally circulating ideas and how they are put into practice locally.

The study of global entanglements is by now familiar terrain in anthropology. Since the early 1990s globalisation studies have analysed local change in relation to global developments in a great variety of ways. Over the last two decades, myriad studies have contributed to deciphering how aspects of 'the global' have caused processes of change through adaptation, appropriation, mixing, rejection or resistance at the local level. Various concepts have been used to analyse relations between global and local from different angles. Macamo and Neubert (2008) for instance suggest studying African local appropriation through the pull factor of attractive 'products of modernity' that cause social change locally (see also Spittler 2003). They point to 'glocalisation', a concept coined by Robertson (1992), or to 'hybridisation' or 'creolisation' (Brathwaite, Shepherd, and Richards 2002) as approaches addressing the mixing of various culturally embedded practices. With regard to terminologies conceiving society as globally entangled and translocally organised, references are made to concepts such as Appadurai's 'scapes' (1996); socio-spheres (Albrow 1997); transnational social spaces in relation to migration studies (Faist and Özveren 2004; Glick Schiller, Basch, and Blanc-Szanton 1992; Pries 1999); connectivity (de Bruijn and van Dijk 2012; Law and Mol 2002; Tomlinson 1999); fluids (Mol and Law 1994); and liquidity (Baumann 2000) as 
capturing "recent transformations in the context of globalisation" (Gertel 2007, 14). Ong and Collier's global assemblages (2005), Eisenstadt's multiple modernities (2002) or Barry's technological zones (2006) certainly point in this direction as well as, on a more methodological level, Marcus's (1995) multi-sited ethnography, which emphasises how global connections demand a more encompassing form of research than former single-place ethnographies.

We maintain that many of the issues these concepts are intended to capture are inherent in our concept of travelling models. At the place of their emergence as much as in every re-territorialisation, models are the result of global assemblages; they are part of the 'fluid spaces' depicted by Annemarie Mol and John Law (1994) or act as connecting devices, and thus perform 'connectivity' in the sense articulated by Mirjam de Bruijn and Rijk van Dijk (2012) and others. They conceptually entail 'local appropriation', as Macamo and Neubert (2008) and Spittler (2003) have put it, as well as 'creolisation' and 'hybridisation', where ideas contained in a model are mixed with locally existing practices. Travelling models are enacted in Glick Schiller, Basch and Blanc-Szanton's (1992) 'transnational social spaces' and involve Eisenstadt's (2002) 'multiple modernities'. Studying travelling models implies a shift from studying structure to studying practices of making things hold together, as George Marcus observed in his 1995 article which reviewed the relevant cutting-edge publications of the previous decade (i.e. approximately 1984-94). The analysis guided by the concept of travelling models could potentially make use of Appadurai's (1996) scapes, as well as of other spatio-geographical concepts such as 'mobile policies' (Peck and Nik 2010).

In other words, the relevant theories of the last 25 years or so that deal with globalisation from sociological or anthropological angles, address similar issues from various perspectives - some more encompassing, some stressing particular aspects, and some highlighting a different perspective from the concept introduced here. To show how we perceive the novelty of our analytic concept of travelling models, we turn our attention from the alternative approaches just mentioned to some older, pre-globalisation theories to make our point. In so doing we also want to articulate a firm theoretical background and context and to avoid the impression that we are merely proposing yet another metaphor to add to an already sometimes irritating avalanche of metaphors.

\section{Travelling Models and Some Theoretical Predecessors}

In our quest to explain the methodological and analytical gains of the travelling models concept, we take recourse to three classical - some might say 
discarded - theories that share a similar impulse, but which also differ in important aspects. All three of the major theoretical strands we look at namely diffusionism (including neo-institutionalism as discussed in Czarniawska and Joerges, 1996), modernisation theory, and rational choice - have been widely discussed and criticised for being too unidirectional, Westerncentric, or for their lack of differentiation. When we take recourse to them, we do so because we realised these theories sought answers to the same questions we were studying: how change in one place is related to developments in other places, and why certain issues that are important in one place are taken up in other places whilst some are not. However, we also show how by applying travelling models our understanding of social processes and change deviates from these earlier takes on a similar problem.

\section{New Dimensions of Diffusion}

Diffusionism proved a popular approach because it offered insights into why certain cultural traits normally of one particular origin - such as the form of a vase or pot, or a particular fashion or religious practice - had spread to other places. The idea was that these traits diffused from cultural centres to peripheral regions by physical processes. Reflecting this line of thinking, the German diffusionists Schmidt and Graebner (Schmidt 1926) advanced the idea of expanding cultural circles (Kulturkreise). The process of diffusion is physically defined as a time-dependent, random motion of given entities, causing their statistical distribution in space. Caused by a concentration (in this case, of culture traits) in one place, the distribution of these traits in outward circles follows, according to the diffusionists, as a natural consequence, if not necessity - and thereby provides the energy for mobility.

The idea was prominent in early American and British anthropology, where it offered material for a dichotomising discussion of how societies evolve, i.e. by going through independent evolutionary stages or by cultural contact and the diffusion of ideas (Tylor 1888; Smith et. al. 1927). Although these lines of thinking developed into different directions within British and American anthropological theory, there were some thinkers - such as Morgan in the United States or Tylor in Britain - who explained social change through a combination of evolutionary and diffusion theories. Petermann (2004) points out that in Germany, in parallel to the Anglo-American strands of discussion, Bastian and Ratzel represented the two positions in a similar way. Influenced by Tylor, Bastian developed a psycho-anthropological theory of parallel evolution while Ratzel understood evolution as a historical diffusion of people, goods and ideas (Petermann 2004, 539). Drawing on Ratzel, Frobenius, an historian of Africa, developed the notion of Kulturkreise particularly in 
connection to West African cultural centres. Cultural traits, he maintained, emanate from a centre and spread into neighbouring areas, thereby forming distinct larger entities such as the Christian Occident or the Far Eastern Kulturkreis (Frobenius 1898). Although Frobenius later abandoned his own notion for being too formalistic, Graebner (1911) and Schmidt (1926) most prominently picked it up in their studies on how languages and cultures dispersed. Diffusionism and evolutionism were later abandoned in favour of new explanations of the world such as functionalism and structuralism. The idea, however, was frequently revived with or without critical discussion (as, for instance, the above-mentioned recourse to neo-diffusionism by Eriksen 1991). Kroeber, for instance, spoke of diffusionism in relation to German-Austrian and British schools, both of which he found too static and too oversimplifying and mechanical (Kroeber 1964). Early in his work, Kroeber anticipated the need for a more finely grained and careful analysis of diffusion, particularly with regard to the causes that contribute to a token's dispersion; he therefore introduced the concept of 'stimulus diffusion' (Kroeber 1940).

The concept of travelling models differs from diffusionism in its explanation of the force that moves ideas. Thus, instead of presuming a kind of physical necessity resulting from the concentration of a cultural trait in one Kulturkreis to be the cause for the token spreading, we qualify why and how a certain model travels and is applied while another is discarded. Furthermore, we consider tokens to move simultaneously from and to different directions, and thus bracket the idea of centre and periphery in a different way. Travelling things create centres and peripheries by their very circulation and by the power relations inherent in them and in the circulation (see Acharya 2009). Situations thus become globally entangled with the help of criss-crossing, travelling and historically changing tokens that thereby become established as models. One might interject that translation clearly relates to the classically anthropological approach of diffusion. However, in studying the translation of travelling models the larger patterns of distribution or diffusion are considered to be the result of innumerable and largely contingent 'single steps on the journey' so that they come second.

\section{Transcending Modernisation Theory to Explain Innovation}

According to modernisation theory, things change because people adapt to life forms that they perceive as more advanced in an evolutionary process - that is to say, a desire to better a situation with the help of new, frequently discernably foreign, concepts and models. The means to achieve economic and social development originate, according to the theory's main thinkers (Lipset 1959; Rostow 1960/1990; Huntington 1968) in industrial and economic innovation. 
With different levels of modernisation, where one side takes the lead and the other follows suit, the world's division into centres and peripheries is central to modernisation theory. To avoid a critical misunderstanding it is perhaps necessary to emphasise that our argumentation refers to the modernisation theories mentioned above. It does not refer to theories of modernity such as those by Max Weber, and the Frankfurt School of Sociology started by Theodor Adorno, Max Horkheimer, Herbert Marcuse, Walter Benjamin and continued by Jürgen Habermas and Axel Honneth. It also does not refer to authors such as Niklas Luhmann and Michel Foucault who developed other sophisticated theories of modernity.

We consider situations instead as co-equal, as in our perspective, models are de-territorialised from one setting and re-territorialised into another. To explain this process, we follow Czarniawska and Joerges (1996) and the authors of their collection of papers who develop the notion of organisational change as brought about by travelling ideas. Once out of their original situation, these ideas gain new meanings and functions in a different situation. Coming from the school of new institutionalism, these thinkers follow Powell and DiMaggio (1983) who, in contrast to old institutionalists, approach institutions and identities as the results of actions and not as their antecedents. They approach the question of how rules become established as being more than regularities this being the core meaning of institutionalisation - but as a complex process closely connected to conflict (Powell and DiMaggio 1983, 4). Ideas, Czarniawska and Joerges (1996) maintain, are normally encountered "in terms of what we already know, and sometimes the encounter barely confirms it; at other times, an idea re-arranges our beliefs and purposes as we translate it; the act of discovery creates a new idea and a new actor" (Powell and DiMaggio 1983, 29). In this way, the re-territorialisation of ideas necessarily constitutes an innovation. This renders thinking about the transfer of ideas more precise than thinking along modernisation lines, which assumes that whole institutions can be transferred (and hardly changed) from one situation to another - a thought that makes no sense at all from the perspective of neo-institutionalism.

It also helps us to respond positively to a criticism directed at actor-network theory. In its attempt to escape, theoretically and methodologically, the trap of circular evidence in social science explanations (in which a phenomenon exists because the social situation, certain beliefs and/or power structures lead to its existence), the idea of actor-networks consists of analysing situations only as results of practice (whereby the 'functions' of existing situations are systematically bracketed). This practice orientation also guides our notion of how the translation of travelling models leads to deciphering how new situations are created. The point is to identify a way to open this black box of 
processes leading to global entanglements, and thus move away from both diffusion and modernisation. Both concepts, because of their fixed presuppositions concerning the direction and form of travelling ideas, have rendered a close observation and study of single steps and aspects impossible.

Here, we consider one aspect in particular to be in need of closer examination - crucial to a model's transfer at all points of its passage is the respective carrier or mediator. Mediators, as Merry (2006) shows, can be individual carriers, but they are best represented by professional groups or experts (Mitchell 2002; Mosse 2008; Rottenburg 2002; 2009a) who appropriate a model and relate it to their own understanding of both the model's origin and intention and the situation into which it is supposed to be immersed. Between these fields, expertise normally becomes invisible and only the result of a model's application to a certain situation remains observable. To make the transfer visible again, it is important to focus on the interstitial spaces. Using the concept of translation, Richard Rottenburg (2002; 2009a) explains this process by looking at the professional body of consultants who cater to the often contradictory objectives of their employer - for instance a development agency - and the necessities on the ground, by only 'loosely coupling' their work with the official aims of the agency they work for (2002; 2009a, 70). The ideas that make up the model necessarily influence the consultant's thinking and actions. At the same time, their understanding of a model depends on his or her existing knowledge and beliefs. As mediator operating in the interstitial space, he or she is in a crucial position to translate the formalised model for the intervention and for the way its future users will presumably understand it. The space between one understanding and another is the space that enables creative new practice, or the space where change happens - the interstitial space. Relating to Rottenburg, Merry (2006) writes about the position of mediators as the being situated in the 'middle' between globally circulating ideas and their local appropriation. She describes in detail what happens at the point in space and time where ideas are translated from one sphere to another. In her account on the mediation of human rights, the middle-actor not only conveys ideas he or she received from non-specified others, but by translating them also holds the power to influence these ideas and to give them a personal twist.

This form of looking at the mediation of ideas has been useful in the field of development studies. Bierschenk, Chauveau, and Olivier de Sardan (2000) and Lewis and Mosse (2006) have focused on the role of local actors in bridging the interstitial spaces between what we call a model's travel and its local reception. Interstitial spaces emerge each time the model is transferred from one person to another or from one place to another. This kind of reflection about development projects relates their sometimes converse impact to the epistemic frames of 
reference at different points of a model's travel. The actor-network-related assumption is that agency lies not in the hands of one organisation and certainly not in the hands of only one single actor, but is distributed between many different actors. For a certain development measure to be enacted in a given situation, a range of heterogeneous actors have to engage, each in his or her frame of reference. And, as Callon and Muniesa (2005) highlight, none of these actors - including so-called centres of calculation - ever holds the full image of the process, or the full responsibility or control over what happens at each single step.

\section{Mediators in Translation. Another Example: Putting Sierra Leonean Gender Mainstreaming into Perspective}

To offer a further illustration of our argument, we refer to the work of Fuest (2010 and this volume) and Thompson (n.d.) who analysed the way in which the Sierra Leonean government made gender mainstreaming a particular focus of its post-war democratisation programme. As a result, women's groups and NGOs mushroomed within the newly peaceful country. Their activities were directed towards securing government support, as well as towards grassroots women's organisations in village farming co-operatives and small-scale business credit groups. As a result of active campaigning, new gender laws were eventually introduced, which, for instance, turned domestic violence against women into a punishable crime. Celebrating their success, the NGOs and women's groups immediately launched programmes to promote the new laws to local women and men - mainly in workshops - instructing them that women were now 'enabled' to take their husbands or other male relatives to court in cases of violent abuse. In delivering these programmes the NGO mediators aimed to use examples that corresponded to the daily experiences of local villagers. This was supposed to make men and women aware of their rights, thereby connecting the international sphere of gender discourses to both the new government legislation and the villagers' life worlds. All in all, as Thompson explains, the news was well-received within the communities: people who had listened to the mediators applauded the new law, some appointed spokespeople to spread the information more widely in the community. The model, one would say, seems to have been translated to the people. The kind of analyses we envisage would, however, go further. First, the mediators' technologies of transmitting the model would be examined as well as those of the people who implement the new law, transferring it and putting it to use at different levels. We should examine the various understandings inherent in the model of Sierra Leonean gender mainstreaming held by different actors, and look at how they relate to the model in everyday practice. This leads to a second step, which highlights the model's actual impact or, in our words, the 
way it is translated locally. Here, Thompson's findings show that although numerous workshops and negotiations had tried to situate the model within the Sierra Leonean setting, women still did not take violators to court.

The reason for this becomes obvious when looking at the prevailing institutions. In the Western context where the model of gender mainstreaming and seeking judicial redress is developed, women who take their relatives to court are able to find institutions to help them when they are threatened or doubted. Such institutional support had not yet been established in Sierra Leone when the gender laws were passed. Without an institutional setting that would support women and protect them from discrimination or further violence, hardly any woman dared to act against her husband or other male relatives. Here, the interpretations offered by Fuest and Thompson differ slightly in emphasis while Thompson depicts innovation in the new awareness the model created among Sierra Leonean women, Fuest investigates the very different meaning 'workshopping' has for the local population.

\section{'Rational Choice' and the Possibility of Establishing a 'Meta-Code'}

Returning now to those preceding theories that sought to link local and global processes, the third important theoretical strand is rational choice. Rationalchoice theory would maintain that an idea is picked up because certain actors calculate it fits their situation and their interests best. This estimate results from rational considerations about usefulness, practicability, economics and political implications (to name just a few parameters). Rational choice relates to travelling models and translation in that the theory also tries to explain why models travel or, in other words, what motivates people to pick up new ideas. In its earlier form, around the 1950s, rational choice focused on larger relations between politics and the economy. Schumpeter (1942), for instance, established a theory of democracy which suggested giving up participation and the common good as basic theoretical preoccupations, and instead introducing a model where political elites are entrepreneurs who produce a specific good - governmental achievement - over which they compete for voters just as companies compete for market share (Green and Shapiro 1994). Later authors - Axelrod (1990) is a prominent representative - focused more on individual patterns of choice. He based his theory on the notion that human action and decisionmaking is primarily motivated by self-interest. Under this premise, co-operation requires an explanation. To explain choice, Axelrod observed decision-making from the perspective of the prisoner's dilemma. ${ }^{3}$ He concluded that altruism

3 In game theory, the prisoner's dilemma is a classical constructed situation of two arrested suspects. Questioned one by one, one prisoner could shorten his prison sentence or go free if 
only works if both players make that choice; otherwise adopting a 'tit-for-tat' approach appears to increase chances of success for individuals, particularly if one person starts to dismiss co-operative behaviour. Closest to our approach of travelling models is the way Coleman $(1986,1990)$ utilises rational-choice theory. He explains individual and collective behaviour from an economic perspective by linking signifiers on the micro-level with a macro-perspective. In other words, specific phenomena on the macro-level influence the decisionmaking processes of individual, micro-level actors, which again change macrolevel phenomena. His famous example is based on Max Weber's theory of Protestant values which influence capitalism (Weber 2001).

Linking travelling models to rational-choice theory, we, however, diverge with respect to the theory's notion of a generally existing rationality. Instead, we align rational choice's rationality with Czarniawska and Joerges's aforementioned re-territorialisation of ideas, and thus with different institutionalised forms of what needs to be known before a decision can be taken and classified as more or less rational. To classify a decision as rational one needs to operate with a fixed notion of the situation one is dealing with - who the actors are; what their temporal orientations, understandings of causality and taxonomies are; and perhaps most problematically, what their interests are. If all these things were known and fixed, the rational-choice argument would work, but would risk being rather trivial. Our view is that this amounts to another trap of circular evidence. The small puzzle that a certain decision raises is solved by reference to a bigger puzzle, in this case the interest. In our perspective the key question therefore rather relates to what constitutes the interest.

In addressing this question, we argue that it is important to examine how all the necessary presuppositions to articulate interest are renegotiated in controversial, fragile situations. One type of negotiated situation arises when people bring new tokens or react to new tokens brought in by others. Here the challenge is to translate between different and often contradicting rationalities. Richard Rottenburg $(2005,2009$ a) considers two aspects to be of prime importance in this case - the first is the notion of an aura that explains why one choice is preferred over another, and the second is the capacity of all actors to

he would testify against the other, who would then receive the full prison sentence. The example is taken to explain why the suspects might not co-operate - that is, give each other an alibi - even if co-operation would help both of them to have shorter sentences. As a result, defection pays off for the one who first defects. He gains more than through co-operation, while the other loses most if he's the only one co-operating. Should both defect, they both lose more than had they co-operated; if both co-operate, they both have shorter prison sentences. 
be critical and reflective about their situation and decision (Rottenburg 2013). This implies the availability of a particular form of 'code-switching' between a 'cultural code' (this is how a situation appears to us or them, but we are aware it could be different) and a 'meta-code' (this is how we provisionally and temporarily agree that things are). The meta-code is indispensable for any communication that is meant to lead to co-operative action; it is the institutionalised version of reality that is enabled by actors' experiences of the world 'as it is' (Boltanski 2011, 60).

Richard Rottenburg thus suggests that a token, in order to be attractive and valued as a model, has to have an aura ${ }^{4}$ - something that is convincing and appealing and at the same time invisible. What makes the token, or aspects of it, appealing depends on many things not covered by rational choice - for one, it depends on the number of previous adaptations. The more sites accept a token as having the potential to be a superior way of doing things, the higher the chances it will be picked up again. This, however, is an act of imitation or mimesis and not of rational choice. The acceptance also depends on the way it is delivered or mediated - a person or corporation with a certain charisma can for example convey ideas better than someone else. Furthermore, the origin ascribed to a model is important. Finally it all depends on how well the model connects to existing circumstances - i.e. the ontological, epistemic, normative and material orders of the receiving site. Thus, an otherwise or elsewhere most practical or 'rational' model might not make sense in a new context and would thus be discarded in favour of a more congenial one. But here again, the existing orders that deal with a travelling token are not taken to be something fixed that would simply determine whether something is incorporated or rejected. In most cases they are re-negotiated.

Rottenburg's 'meta-code' refers to the reality construction that is necessary among parties with diverging positions to agree on the use and superiority of this rather than another model. To be able to negotiate between different and sometimes conflicting epistemic understandings of the world or rationalities - demands a form of openness which allows all involved actors to search for a way of balancing or adjusting the rationality of the others. This process mainly depends on the ability to be reflective about one's own

4 Following Walter Benjamin, Richard Rottenburg defines aura as the persuasive character, the vibe of a token (with Benjamin it was the vibe of a piece of art) that demonstrates originality, authenticity, uniqueness, inimitability - in short, it arrives as 'the real thing' and thus as distinct from a 'poor imitation'. He maintains that aura often becomes an invisible aspect of power when it persuades or misguides others to do what they would not have done otherwise. 
conception of rationality, and to recognise that other actors might have a very different background understanding of what is rational. It is only on this basis that a code can and needs to be established to effectively communicate between different rationalities. Evaluative categories such as efficiency, fairness or legitimacy can serve as media for what Richard Rottenburg (2005) has termed the 'formulation of a meta-code'. This code renders actors from very different epistemic backgrounds capable of agreeing on situation-specific terms of interaction or co-operation. They do this in a reflexive way, balancing between competing rationalities and social-world understandings, for which simply no a priori meta-code exists.

In other words, while rationality cannot serve as a given and universal metacode, a meta-code is still indispensable for communicating justifications for actions and decisions that require some sort of legitimacy. All that is available, though, are temporary and provisional meta-codes that are used to agree on a rationality for the purpose at hand while bracketing out the unavoidable contradictions and contingencies. This also applies to the objectivity claim of the code in which social science speaks about the workings of the meta-codes agreed upon by actors. Rather than claiming the status of a universal metacode, the language of social science is an infra-code that allows us to follow the different steps of translation and the meta-codes of the actors, which often follow the logic of rational choice (Latour 2005, 49).

Thus, when using travelling models as a concept to analyse the intermediate steps of global and local change, we must examine which forms of confrontation and mediation are put to use in a given situation among differing, or even competing, concepts of rationality. This implies enquiring into the forms of legitimacy that are appealed to. In this way, the concept is also useful for the examination of normative statements about desired or undesired changes without setting a-priori benchmarking criteria. The analysis of open discussions about observable assessment criteria would replace large and demanding concepts such as 'progress' or 'freedom', 'fairness' or 'equality'. With its universal applicability, our approach addresses innovation by studying encounters of different life-forms and the difficulties inherent in the analysis of the desired or undesired consequences of the encounters.

\section{Travelling Models - What is the Concept Good for?}

The notion of travelling metaphorically depicts translation. In this chapter we aim to show how the specific character of processes of travelling or circulating between different situations becomes the focus of study and the basis of 
theorising. The thing which travels or is transferred needs to be translated this implies being improved, subverted, appropriated and annexed. This thing is a token that transports ideas and becomes a 'model' by being picked up. The analytical concept of travelling models thus highlights the fact that changes happen in the interstitial, in-between spaces and steps, where set-ups are outlined and separable units are negotiated in interactions that cross time and space. In certain contexts it might appear more appropriate to speak of travelling technologies, in others of travelling significations.

This approach enables reflection about social and cultural change in a world that is characterised by sophisticated economic, communicational and legal integration that causes an exchange of ontological, epistemic, normative and material orders with far-reaching consequences. When selecting the travelling model to study, both comprehensive and detailed forms of materialising or objectifying ideas can be considered. This form of analysis covers larger historical developments by, simultaneously, focusing on very detailed and particular events - or, most importantly, the relations between them. 'Travelling models' offer a frame that is sufficiently encompassing to include studies that not only focus on recent forms of global entanglements, but also account for events and technologies related to the times before the last wave of globalisation became one of the main referential frames.

A further motivation for the kind of analysis we are proposing is the desire to gain sufficient understanding to formulate relevant critiques of processes of exclusion, oppression, humiliation, and the violation of rights. Saying this, we are aware that theories of translation risk focusing, in hermeneutic tradition, too exclusively on the process of understanding. We therefore suggest paying particular attention to practices, materiality and technology. Another danger when looking for the possibilities of critique lies in the temptation to abandon the infra-code of detached analysis and smuggle in a meta-code as an Archimedean point. In most cases this hidden switching from infra - to meta-code with its implicit Archimedean point is a theoretical construction with its own problematic positionality - often unveiled as 'Western'. We thus underline the importance of staying true to what we termed infra-code and following the critique of the actors mostly articulated in meta-codes (what others have called strategic essentialism).

In this first part of the introductory chapter we distinguished our approach from earlier and competing ways of examining how change in one place is related to developments in other places. We focussed mainly on theories of diffusion, modernisation and rational choice. While we acknowledge the questions raised by these theories, we differ from them on several important points. One major difference is that we argue that tokens are not embraced because 
they have any inherent characteristic or power - such as being rational, modern, close to human nature or otherwise superior. We rather argue that the process is contingent since tokens need to be translated and thus changed unpredictably in order to travel, to connect to new orders and thereby become models which over time may be replaced by others. Another major difference is our methodological strategy, inspired by practice theory and pragmatism, which aims to avoid the trap of circular evidence by not explaining social practice through reference to a larger frame (which can be even more questionable than the practice being explained in the first place). Finally, with translation theory we do not claim to offer a meta-code that would surpass our own positionality; we are content with an infra-code that allows us to follow the different steps of translation and the meta-codes of the actors, as well as their critique. Following these three principles in an attempt to minimise theoretical assumptions about the world, we are able to generate theories related to observable empirical processes of world-making. In the second part of this introductory chapter we elaborate on the question of travelling models in conflict management.

\section{Travelling Models in African Conflicts}

\section{Comparison and the Study of Conflict Management}

We have already mentioned in the preface to this book that our focus on Africa was primarily a result of the research that forms the basis of most chapters being carried out in the context of a larger programme for the Volkswagen Foundation on "Knowledge for Tomorrow" for Africa. Having embarked on this focus, however, we developed a certain unease with comparative research traditions in area studies, particularly as they related to the topic of conflict and conflict management. Instead of looking for authors who work on similar questions on other continents we decided to concentrate on the issue of comparison within African studies.

Our unease was triggered by the observation that practical and academic interests in conflict management often circle around the question of 'what works' in conflict management and, more importantly to some, the question of 'what does not work' or what may even prolong or exacerbate conflict. Much research in this area thus takes the question of 'implementation' as a starting point and this can have unhelpful consequences for the research. Such questions have increasingly prompted the demand for better scientific evidence, which is associated with the development of a comparative research design in studying conflict and conflict management. As Andreas Mehler points out, research on 
conflict management in the field of area studies has been experimenting with different types of comparative approaches (Mehler 2005). In principle, however, most comparative approaches compare the same factors in different yet similar 'conflict settings' to identify and test the independent variables which determine success and failures in conflict management as the dependent variable (Mehler 2005, 116). Such evidence would, in turn, be the foundation for putting - or translating - conflict managing models into practice.

But what are the objects of comparison - in this case the 'conflict setting' in the research traditions in area studies, particularly relating to Africa? Starting with the most obvious, the 'area' - a significant critique has been the way area studies construct their objects of comparison by drawing on too narrow an idea of 'area' as the unit of analysis (Chabal 2005a; Szanton 2004). Chabal maintains that in most cases 'area' is mainly defined as a culturally or territorially bounded unit, which ignores the fact that units of analysis are always creatively constructed in relation to the underlying research question (Chabal 2005a, 477). More generally, Jörg Niewöhner and Thomas Scheffer suggest reviving the ethnographic notion of comparison, according to which "objects of comparison are not found 'out there', but are constructed through 'thick comparison' (Niewöhner and Scheffer 2010). For these authors ethnographic research traditions can be brought to bear on conventional comparative research designs by going beyond the underlying assumption that 'areas' exist and can be compared with each other in respect to a particular policy or model. Instead, as we will elaborate below, comparing - being a particular form of translation needs to be considered in the performative idiom, which emphasises how these practices do not represent a reality, but essentially construct the objects under comparison and ultimately bring new objects into being.

These considerations are particularly crucial for the field of area studies and the disciplinary developments towards various forms of global studies. In these fields comparative approaches have relied heavily on highly contested categories such as the nation-state, culture, territory, tribe or community, which do not suit the reconstruction of conflict and conflict management as a field of inquiry for comparative analysis. It is important to note that the scholarly critique on which we elaborate here is not purely an academic debate about different scientific epistemologies. On the contrary, this debate interlinks research and political intervention surrounding the phenomenon of conflicts in Africa. As violent conflict and conflict management have been recurrent topics in area studies concentrating on Africa, some scholars, such as von Trotha (2000), Tilley (2011) and Rottenburg (2009b), criticise the way in which the continent came to figure as a global political laboratory to experiment with Western models of political authority and statehood. Throughout Africa's recent history, 
some of these experiments had devastating effects, producing novel forms of sovereignty and political authority in which violence and disorder at times figure as political instruments (Chabal and Daloz 1999). Authors such as Chabal (2005a, 2005b) and Szanton (2004) have explicitly accused area studies of being complicit in the production of such 'disorder' (Chabal 2005a; Szanton 2004).

Mahmood Mamdani (2001), by similarly connecting scholarly debate and local practice, argues that this research tradition produces and reifies 'ethnicity' as a political identity, which bears the inherent danger of being misused as an easy justification for mass violence. Szanton (2004) has summarised the scholarly critique of area studies as a perception that the discipline is

at best, naively, at worst, intentionally - imposing their own personal and/or national agendas and variously idealized or mythologized formulations of the historical experience of 'the West', both to explain, and most often in the process, to denigrate other societies that have almost always been in one way or another, politically and economically subordinated.

SZANTON 2004, 23

With the end of the Cold War as a generally acknowledged turning point, research on conflict has attempted to accommodate global trends such as neoliberalism and the erosion of state monopolies on violence as globally observable phenomena (Bayart, Ellis, and Hibou 1999; Callaghy, Kassimir, and Latham 2001; de Waal 1997; Ferguson 2006). More recently Hardt and Negri (2000), in their successful book Empire, have more provocatively attempted to come to terms with such global trends by suggesting novel forms of imperial sovereignties. However, this thinking relies overtly on the notion that African countries in particular - many of which are considered 'failed states' - demonstrate that imperial forms of sovereignty have replaced the 'modern' sovereignty of the state. But these accounts, as Dunn has observed, incorporate the marginal position of the African continent into public and scholarly debates by simultaneously excluding it (Dunn 2004, 151).

Frederick Cooper (2005), critiquing the epistemologies in area studies, suggests that research needs to consider topics such as conflict and conflict management on the African continent in relation to the various shifting territorialising and re-territorialising tendencies in the production of global orders in Africa (Cooper 2005, 92). Research needs to consider how ideas, models and technologies on conflict management are re-territorialised into a heterogeneous network of governmental and non-governmental organisations, international organisations and civil society, as well as examining the way they are entangled in the production of order. 


\section{Translation and the Study of Conflict Management}

This book tackles the question of how to study conflict and conflict management without subscribing to a narrow notion of comparison. Instead we ask how objects are made commensurable. And how comparability is produced. In order to move beyond the culturalist framework inherited from 'realist' research traditions we take the notion of translation as a key point of departure in the construction of research objects. In this regard the chapters take up the 'translational turn' in social sciences to rehearse a comparative perspective in studying conflict management in African settings (Schäbler 2007, 39). According to Rottenburg's account of translation, the categories 'conflict', 'African societies', 'ethnic group', or 'community' cannot be taken as objective representations of empirical reality. Moreover, Rottenburg insists that scholarly controversies around these representations "cannot be resolved according to the model adaequatio rei et intellectus, the equation of thought and thing" (Rottenburg 2002/2009a, xxxii). Instead, he maintains, one needs to study the practices of representation itself, which reveal that

one is never dealing with a single referent but rather with a diversity of internal or transversal referents that have been organized into a chain such that they support themselves as they proceed along it. From this perspective, a representation is always a cascade of re-re-...representations. Because the practice of representation is best understood as a translation this [can be called] a translation chain.

ROTTENBURG 2009A, XXXII

Taking up Richard Rottenburg's approach, we explore such translation chains by following a model's trajectory. Studying the travel of models stands in relation to a set of anthropological notions about 'circulation', 'flows', and 'translation', which are widely used to discuss the diversity of phenomena associated with the term 'globalisation' and its local effects (Eriksen 1991; Ong and Collier 2005; Rottenburg 2005). Globalisation has too often been used without sufficient accuracy, and, as various scholars suggest, we may need alternative and more precise concepts to capture the emergence of specific global and local properties in long-distance connections (Cooper 2005; Rottenburg 2009a). As we have already elaborated above, we assume that models can have very specific origins in a particular time and space, from which they are then abstracted and de-territorialised in order to travel to another setting.

In this way, we approach conflict management as a distinct object of professional practices and scientific expertise. Thus, instead of thinking in terms of a one-sided flow from the 'West to the Rest', we prefer the notion of travel as it 
avoids a global-local binary. Rather, as Peck and Theodore define mobile policy models, the notion of travelling does not mean "simply traveling across a landscape - they [policy models] are remaking this landscape" (Peck and Theodore 2010, 170). In other words, by being transferred, models assemble arrangements of people, artefacts and knowledge. The study of travelling models in conflict management is essentially a translocal process, which takes place neither in some vague 'global' space nor in a narrowly defined 'local' space, but instead in the interstitial spaces, where conflicts and their management are subject to dynamic adaptations, negotiations and contestations. In this respect the chapters in this book tie in with studies in the field of development aid, which establish the central role of experts as 'norm entrepreneurs' (Finnemore and Sikking 1998) or of local development 'brokers' who actively influence local arenas by making use of internationally acquired knowledge (Bierschenk, Chauveau, and Olivier de Sardan 2000). They let development projects "become real through the work of generating and translating interests" (Lewis and Mosse 2006, 13) and acknowledge that such projects often generate "complex and unintended effects" (Mosse 2008, 120; Rottenburg 2009a).

We want to emphasise that the notions of travel and translation do not imply any linear evolution or direction, for instance from the global to the local or from North to South. Instead we ask how people, things, and ideas travel between various fields of practice. The authors collected in this volume aim at understanding the translation process that makes models travel, and further, to focus on who unpacks and (re-)enacts the technologies a model contains. They, thus, set out to investigate particular sets of disparate elements, which have been assembled into distinct models that render conflicts into objects targeted by interventions. Bringing the model into focus, the authors investigate, for instance, where models originate from, which practices and institutions legitimate them, and to what extent such questions help in addressing the consequences a model reaps. In this regard models are studied as entailing technologies to produce particular versions of social order. In other words, by looking at sites of translation, the contributions do not analyse conflicts per se, but programmes that rehabilitate conflict-torn regions, policies to counter violence and crime, or internationally developed directives as part of peace agreements or legal frameworks; which can all be comprised under the umbrella term of technologies of social ordering that aim at managing conflict.

\section{Framing Conflicts}

The idea of conflict management may appear to be intuitively clear. However, as highlighted above, it is more difficult to find an analytically precise definition of conflict management that can be applied to the diversity of conflicts in 
different settings. But this may not be a contradiction. Rather, as this book suggests, actors seem to follow and imitate designated trends in their field of expertise, which travel as models in conflict management from one conflict to the next. ${ }^{5}$ Experts in the domain of conflict management, as in the broader field of development co-operation, often depict models as neutral instruments in providing an objective representation of the empirical world.

The chapters in this book follow the travel of models in conflict management with the aim of exploring the production of order and disorder they trigger in various contexts. As the contributions will show, these models of conflict management do not necessarily relate directly to a conflict's solution or even to a secession of violence. Rather than being unidirectional in that sense, they involve a multitude of locally adapted and globally circulating practices that lead to mediation, adjudication and negotiation, but also to practices of rebelling, fighting and preventing a conflict's termination. Practices evolving from conflict-managing models can thus be more or less successful or they more or less fail in finding ways to end conflict; sometimes conflicting parties may abandon them, to perhaps pick them up again later in a varied form. By referring to them again and again, the practices come to be socially embedded procedures as the rational and legitimate way-of-doing-things-in-order-to-achieve-certainaims, and as such they may become institutionalised as new and creatively adapted technologies of social ordering.

Although adapted to specific local circumstances, conflict-managing technologies necessarily change over time. They are amended, adjusted to cater for situations that differ from the preceding ones, involving, for example, new possibilities for negotiation and jurisdiction, but also changes in the types of arms, the establishment of new alliances, and changes in leadership. These changes are, again, not linear. To the contrary, different technologies of conflict management overlap by being used simultaneously; sometimes, as some of the chapters will show, they contradict each other and lead to new contention.

At any point in time, and particularly since the global spread of conflict intervention and humanitarian and development aid, new actors and new conflict-managing technologies may emerge. Local actors in conflict address international agencies with their agendas and principles of intervention in local conflict. At the same time - in another twist - internationally conceptualised ways of dealing with conflicts are constantly introduced and offered to the actors in the conflict. Some of them, although opposed, are implemented

5 This argument draws on Barbara Czarniawska's suggestion of likening the travel of organisational models to the spread of fashions (Czarniawska and Joerges 1996, 24). 
against the will of all or some local actors. When decisions are being taken as to which form of conflict management will be used, power asymmetries inevitably come into play - a situation that Acharya (2004) aptly encapsulates with the question "Whose norms matter?" Here, external consulting, political negotiations with international partners, humanitarian and development aid as well as questions about the interests of international agencies in relation to 'sovereign' governments enter the discussion on conflict and conflict management. The effect of political interest in aid relations has, in particular, been taken up in a number of recent contributions to volumes edited by Bornstein and Redfield (2011) and Fassin and Pandolfi (2010). Sarfaty (2012) addresses the particular case of the World Bank and its internal resistance to a human rights framework.

This focus on conflict management practices does not preclude the fact that travelling models also provide essential technologies for running conflicts. And although we do not focus on technologies of conducting conflict, theories derived from such studies also occasionally make reference to what we call travelling models. Thus, in an introductory text to a volume on violence in Africa, Chabal (2005b) stresses the apparent 'modernity' of conflict practices. He advances the example of young fighters in the Sierra Leonean civil war whose brutality he does not regard as 'primitive', i.e. following the model of "some ancient African god", but rather the American war-movie hero Rambo (Chabal 2005b, 12). By comparing, however vaguely, a travelling model coming from Hollywood to the Sierra Leonean civil war, he also insinuates the local translation of Rambo's fighting technologies. Richards (1996) also refers to modernity when he maintains that war in Sierra Leone was not a result of ethnic rivalry, an indicator of 'barbarism' or a sign of 'the coming anarchy', but based on what he regards as rational deliberations of a group of rebel fighters, well-versed in global interconnections. Reflections about the apparent 'modernity' of (local) conflicts thus interrelate strongly with the trend to studying globalisation, or, as we would call it, the mobility of elements that have been assembled into models.

\section{Organisation of the Book}

The case studies selected for this book focus regionally on Liberia, Sierra Leone, Chad, South Africa, Sudan and Ethiopia. They address both rapid current transformations on the continent and long-term political, technological, medical, economic, and other social processes. Instead of comparing regional contexts or conflicts themselves, the chapters compare models - understood as 
technologies of social ordering. They analyse the origins, trajectories and the conflict-managing solutions these models entail. Thematically, the chapters address models of post-war reconstruction, democratisation, revenue-sharing, power-sharing, community policing, and mediation. Some of them have already been deployed in other settings before and may travel to further settings in future. In this regard, models as technologies of interventions are always mutating and the chapters provide detailed ethnographic analysis of their transformations, uses and effects.

The book's contributions compare the way models render conflicts into technological procedures. To reflect this, we have divided the chapters into three parts: (1) Redefinition of Models in Expert Interventions, (2) Models in Institutions of Political Ordering, and (3) Models Targeting Community Mobilisation as an Element of Social Ordering.

\section{Part I: Expert Interventions and Local Redefinitions}

In the first part, three chapters take the local redefinition of models of 'expert intervention' into focus. We use the term 'expert' to refer to humanitarian, development or economic specialists who both develop and apply models in their field of expertise. The three chapters in this section take as their point of departure the interstices between the intended intervention and a thorough observation of the model's reception. This part begins with a chapter by Veronika Fuest, a specialist herself, not only in long-term anthropological research, but also in development aid interventions in Africa as evaluator and commentator. Her contribution focuses on Liberian non-state actors as mediators of travelling models in post-conflict attempts to build peace. Her 'model' is what she calls 'workshop culture'. Fuest shows how this culture resulted from a widely accepted view that considers so-called failed states to have lost their regulatory powers during and after civil wars, particularly in Africa. As a result, peace-building policies have, on the one hand, generated an expansion in the claims of non-governmental organisations to strengthen civil-society institutions, including the representation of groups that are generally perceived to be social subordinates. On the other hand, some development experts, international NGOs in particular, champion what they perceive as traditional institutions - represented by social elders and local political leaders - often regarded as social capital in reconciliation and conflict resolution. By following the effects of such workshop culture, she wonders who actually 'owns' the workshop, thereby rendering local adaptations to the point of re-appropriation of this expert terrain her prime focus.

The expert intervention in the next chapter originates at the World Bank and targets a newly oil-producing country, Chad. The chapter is written jointly 
by Remadji Hoinathy and Andrea Behrends and combines their research Remadji Hoinathy for his PhD in anthropology at the Martin Luther University of Halle-Wittenberg in 2012 and Andrea Behrends in her role as one of three principal investigators of a co-operative research project on oil production in Chad and Niger. They focus on how the expert-driven, economic- and development-oriented World Bank model of revenue-sharing has been taken up in Chad. With the aim of distributing the newly gained oil revenues in a fair and transparent manner in favour of development projects, this model was instituted to try to prevent the negative outcomes of high resource rents in otherwise very impoverished countries -the so-called resource curse. It aimed at bettering the country's social infrastructure by legally attributing large percentages of oil revenue to present and future development and thus preventing the potential for conflict by 'bringing wealth to the people'. The model was, however, unable to prevent the country from being plunged into several years of conflict - mainly rebellion and counterinsurgency - which had reignited in neighbouring Central African Republic, Sudan, and in Chad itself, where rebels are continuing to fight the government and each other. Hoinathy and Behrends show that although the World Bank advanced a rhetoric of development, the main intention of the World Bank's intervention has been economically oriented - to make oil production profitable in Chad. Arguing against popular notions of the 'resource curse' theory, Hoinathy and Behrends suggest following the intricate process of this model's adaption. They argue that the model's translation requires analysis on different levels in order to reach an understanding of its very differential impact.

In the final chapter of this first part, Lydie Cabane takes a political-science angle on travelling models in relation to disaster management. Cabane is a post-doctoral researcher at the Center for the study of Health, Science, Medicine and Society (CERMES3) in Paris. Her interests include global health, risks and disasters, science and policy in a transnational world. Her account of the translation of conflict into 'disaster risk' in South Africa has been inspired by the theoretical canon of the actor-network theory. Placing humanitarian activists and development agents at the centre of her research, she focuses on another level of a model's translation - namely the mediation of a model. Cabane finds that throughout its democratisation South Africa was led to redefine conflicts as disaster risks, enabling a redefinition of the space and management of conflict in a country shaped by a history of violence. This translation of conflict marks the expansion of a global model supported by the United Nations, circulated by experts, and incorporated into legislation and specific management tools. Cabane looks at the situation in which disaster management was first adopted as a framework in South Africa and then analyses the 
way it came to be applied during the xenophobic attacks on foreigners - mainly from Zimbabwe - in May 2008.

\section{Part II: Institutions of Political Ordering}

The three chapters in the book's second part give attention to political institutions on different national and international levels and the way travelling models have influenced technologies of political ordering. Mutasim Bashir Ali Hadi's research as a PhD candidate at the Department of Sociology and Social Anthropology at the University of Khartoum took him to South Darfur, Sudan, where his family originates. Being of Southern Darfurian Arab origin, his access to the Arab communities in this part of Darfur was immediate and possible even during escalations in violence in the Darfur War following the outbreak of the conflict in 2003. He looks at the model of 'power-sharing', which represents a policy widely used in internationally guided peace negotiations as a transitory measure to go from war to peace, and from military dictatorship to civil democracy. It implies that two or more opposing parties share political power and national wealth to ease tensions originating from the desire of marginal groups for inclusion. With power-sharing as the basis and often the outcome of peace negotiations, negotiators usually expect that dialogue will be possible in the future and that democratic structures will eventually evolve. In his example, Mutasim describes how power-sharing, brought about by two different peace agreements - the internationally mediated Comprehensive Peace Agreement of 2005 between North and South Sudan and the 2006 Darfur Peace Agreement - led to the converse on the ground. Instead of bringing peace to different groups with varying involvement in the Darfur War, it resulted in an increased desire to divide into ever-smaller communities. This was due to a complex understanding of power-sharing, a concept that, as Mutasim shows, had been known to the people of this area as el oud, an Arabic term literally describing a small piece of wood. As a social term it depicts a share or a right. Mutasim highlights that as a political concept el oud is used to mediate in situations of competition or (potential) conflict between individuals or groups by distributing power in a way that is considered locally as fair. But he also found that the people in his research area translated the power-sharing agreements that formed part of the national and regional peace agreements into ways of opposing each other for an equal share of local and regional power. In a chain of reactions, more and more groups and sub-groups aimed at having a direct link to the national government by acquiring their own 'locality' or administrative post. This strategy serves to separate the formerly cohabitating groups from each other by putting them simultaneously under the direct control of the national government - reminiscent of the divide-and-rule policy 
that characterised British colonial rule. Mutasim thus witnesses a conflictmanaging model's unintended consequences - in this case, the escalation of conflict as a direct result of how people translated the basic assumptions of the various peace agreements.

Dejene Gemechu's study of a travelling model in Ethiopia documents several similarities with developments in Sudan. Although not in open civil war, ethnic strife has been widespread in Ethiopia over the last few decades. The model of 'ethnic federalism', introduced to Ethiopia in 1991 with the intention of enabling devolution and appeasing latent and open conflict, led, in fact, to similar divisions as those described by Mutasim. Like Remadji Hoinathy, Dejene Gemechu was awarded his PhD in anthropology at the Martin Luther University. He now works in the social science stream at Jimma University in Ethiopia. He notes in his study that traditional institutions dealing with conflict management have experienced an unprecedented and rising surge of interest in Ethiopia since 1991. State agencies as well as international NGOs and civilsociety groups have begun using measures such as traditional peace conferences, mediation by clan elders and compensation payments in kind or cattle as prominent methods of re-establishing peace in areas of frequent inter and intra-ethnic conflict and violence. Dejene demonstrates that among the Borana-Oromo agro-pastoral populations of the Ethiopian lowlands, these conflicts, have, in the past, been mainly about access to land. One peace conference was convened by the Swiss Red Cross, but modelled on what they thought of as traditional Ethiopian peace negotiations. Using the example of the Allona Peace Conference, Dejene shows how Oromo conflict mediation is boosted by the presence of government agencies and NGOS, making it a local model travelling to the national and even international spheres. Depending on the sensitivity of the conflict at stake and on the time and care given to the mediation process, these newly rediscovered measures seem to reap certain positive results. On the one hand, decisions taken in the 'traditional style' of the populations involved can be expected to receive wider recognition and there is thus greater likelihood that people will comply with them. On the other hand, however, the ethnic federalist policy can mean that the government's intentions could be characterised as trying to 'buy legitimacy' among the local populations by empowering traditional authorities, while new conflicts evolve among the different ethnic groups who contest their respective inclusion into national and regional political decision-making.

As an anthropologist at the University of Cologne, Mario Krämer has worked extensively in the KwaZulu-Natal region in eastern South Africa. His contribution provides insights into triggers of conflict as well as (traditional) conflictresolution mechanisms. He maintains that since the early 1990 s the travelling 
model of democracy has been much in demand in sub-Saharan Africa. In his contribution to models in institutions of political ordering, he focuses on local post-apartheid politics, and illustrates the translation of the liberal democratic model - as enshrined in the South African constitution - under specific local circumstances. Given a legacy of chronic violent conflict, new forms of political power have emerged in recent years. The clearest example of this divergence from, and conversion of, the democratic model is the dualism of neo-traditional and democratic institutions in local government. The chapter examines the co-operative as well as conflicting relations between democratically elected and neo-traditional actors and discusses the implications for post-apartheid democracy.

\section{Part III: Mobilisation and Communities in Social Ordering}

When devising models that aim at fostering social and political change, particularly in preventing conflicts or rehabilitating their effects, 'communities' of different kinds suggest themselves as an adequate, even convenient target for policymakers and thus for the implementation of travelling models. Depending on how communities are defined, community members can also be important actors in appropriating models in a way other than intended. The chapters in the final part of the book start out from the community perspective to investigate the very differential effects of models. Sylvanus Spencer, an historian by training, opens the contributions in this section. With a master's degree in history from the Fourah Bay College in Freetown, Sierra Leone, he undertook extensive qualitative field research for his $\mathrm{PhD}$ on travelling models at the same institution. Inspired by Geertz's idea of 'thick description' - the detailed ethnography and subsequent analysis of an event or a situation - Spencer concentrated on the post-war 'democratisation' in his country. In the course of his research he came to focus on one aspect of democratisation, namely the notion of 'freedom of expression' and he traces the development of this model from an historical perspective following its introduction to post-war Sierra Leone and Liberia. Thick description was particularly valuable when looking at the various implications of free expression during the 2008 elections in Sierra Leone. Taking youth as a category for his study of pre-election campaigns and people's reactions to them, Spencer examined song lyrics, the performance of singing and the controversies created by both texts and performances in his analysis of the model's translation. He shows that translations can move in very diverse, if not outright contradictory and conflicting, directions, and his research thereby encapsulates one of this book's essential findings - that (often highly acclaimed) models in conflict management need a thorough assessment of the local terrain if we are to anticipate what will happen to them 
when being implemented. In Sierra Leone, as a consequence of the events described by Spencer, members of the elite, traditional elders and influential politicians sought limits on free expression, fearing their formerly uncontested positions would be jeopardised. Interestingly, he also found that government officials, development workers and radio broadcasters who were in favour of free expression claimed that destructive publishing could threaten democracy; they therefore advocated 'responsible' handling of this travelling model. And, indeed, in common with the case of oil-revenue distribution in Chad, and with domestic violence in Sierra Leone and the government's efforts there to introduce gender mainstreaming measures, a free press could ultimately only operate as part of a much larger institutional arrangement. Without institutional arrangements that are conducive, models may trigger developments that go in a very different direction than was planned by those conceptualising the model.

In the book's final chapter, Tinashe Pfigu and Kees van der Waal reflect on 'community policing' as a model aimed at managing small-scale conflict and crime in the South African region around Stellenbosch. Here, the country's distinct history of apartheid and the anti-apartheid struggle, as well as prevailing class and 'racial' differences, provides a very specific political climate as background for travelling models. As Pfigu originates from Zimbabwe, where she completed her master's degree in social anthropology, she provides a perspective that is close but once removed from the South African context. Kees van der Waal, professor of anthropology at the University of Stellenbosch, supervised her work and contributed with a case study from his own research. Together their research has focused on local-level practices of crime prevention, influenced by national programmes such as the National Crime Prevention Strategy of 1994. Pfigu and van der Waal show how community policing is meant to encourage partnerships between civil society, business, government, police and local people in dealing with crime, but when comparing three different neighbourhoods they conclude that the particular technologies of this model can be unpacked and translated very differently, based on existing concerns within each of their research sites.

\section{References}

Acharya, Amitav. 2004. "How Ideas Spread: Whose Norms Matter? Norm Localization and Institutional Change in Asian Regionalism." International Organization 58 (2): 239-75.

Acharya, Amitav. 2009. Whose Ideas Matter: Agency and Power in Asian Regionalism. Ithaca, NY: Cornell University Press. 
Albrow, Martin. 1997. The Global Age: State and Society Beyond Modernity. Stanford, CA: Stanford University Press.

Alt, James E. 1987. "Crude Politics: Oil and the Political Economy of Unemployment in Britain and Norway, 1970-85." British Journal of Political Science 17 (2): 149-99.

Appadurai, Arjun. 1996. Modernity at Large: Cultural Dimensions of Globalization. Minneapolis, MN: University of Minnesota Press.

Auty, R.M. 1993. Sustaining Development in Mineral Economies: The Resource Curse Thesis. London: Routledge.

Axelrod, Robert. 1990. “The Problem of Cooperation." In The Evolution of Cooperation, edited by Robert Axelrod and Richard Dawkins, 3-24. London: Dawkins, Richard.

Barry, Andrew. 2006. “Technological Zones.” European Journal of Social Theory 9 (2): 239-53.

Bauman, Zygmunt. 2000. Liquid Modernity. Cambridge: Polity Press.

Bayart, Jean-Francois, Stephen Ellis, and Beatrice Hibou. 1997/1999. The Criminalization of the State in Africa. Oxford: James Currey; Bloomington: Indiana University Press.

Behrends, Andrea. 2008. "Fighting for Oil When There is No Oil Yet: The Case of the Chad-Sudan Border." Focaal 52: 39-56.

Bierschenk, Thomas, Jean-Pierre Chauveau, and Jean-Pierre Olivier de Sardan. 2000. Courtiers en Developpement: Les Villages Africains En Quãête de Projets. Paris: Association euro-africaine pour l'anthropologie du changement social et du développement; Bloomington, IN: International African Institute.

Boltanski, Luc. 2011. On Critique. A Sociology of Emancipation. Cambridge: Polity Press.

Bornstein, Erica, and Peter Redfield. 2011. Forces of Compassion: Humanitarianism Between Ethics and Politics. Santa Fe, NM: School for Advanced Research Press.

Brathwaite, Kamau, Verene Shepherd, and Glen L. Richards. 2002. Questioning Creole: Creolisation Discourses in Caribbean Culture; In Honour of Kamau Brathwaite. Kingston, Jamaica: Ian Randle; Oxford: James Currey.

Callaghy, Thomas M., Ronald Kassimir, and Robert Latham. 2001. Intervention and Transnationalism in Africa: Global-Local Networks of Power. Cambridge: Cambridge University Press.

Callon, Michel, and Bruno Latour. 1981. "Unscrewing the Big Leviathan: How Actors Macro-Structure Reality and How Sociologists Help Them to do so." In Advances in Social Theory and Methodology: Towards an Integration of Micro- and MacroSociologies. Ed. Karin Knorr-Cetina and Aaron Victor Cicourel, 277-303. Boston: Routledge \& Kegan Paul.

Callon, Michel, and Fabian Muniesa. 2005. Economic Markets as Calculative Collective Devices. Peripheral Vision: 1229-1250.

Chabal, Patrick. 2005a. "Area Studies and Comparative Politics: Africa in Context." Afrika Spektrum 40 (3): 471-84. 
Chabal, Patrick. 2005b. "Violence, Power, and Rationality: A Political Analysis of Conflict in Contemporary Africa." In Is Violence Inevitable in Africa? Theories of Conflict and Approaches to Conflict Prevention, edited by Ulf von Engel, Annamaria Gentili and Patrick Chabal, 1-14. Leiden: Brill.

Clifford, James, and George E. Marcus. 1986. Writing Culture: The Poetics and Politics of Ethnography; A School of American Research Advanced Seminar. Berkeley: University of California Press.

Coleman, James S. 1986. Individual Interests and Collective Action: Selected Essays. Cambridge: Cambridge University Press.

Coleman, James S. 1990. Foundations of Social Theory. Cambridge, MA: Belknap Press.

Collier, Stephen J., and Aihwa Ong. 2005. Global Assemblages, Anthropological Problems. Malden, MA: Blackwell Publishing.

Cooper, Frederick. 2005. Colonialism in Question: Theory, Knowledge, History. Berkeley: University of California Press.

Czarniawska, Barbara, and Bernward Joerges. 1996. "Travels of Ideas." In Translating Organizational Change, edited by Barbara Czarniawska-Joerges and Guje Sévon, 13-48. Berlin: De Gruyter.

Czarniawska, Barbara, and Sevón Guje, eds. 1996. Translating Organizational Change. Berlin: De Gruyter.

de Bruijn, Mirjam, and Rijk van Dijk. 2012. The Social Life of Connectivity in Africa. New York: Palgrave Macmillan.

de Waal, Alexander. 1997. Famine Crimes: Politics and the Disaster Relief Industry in Africa. London: African Rights and the International African Institute; Oxford: James Currey; Bloomington: Indiana University Press.

DiMaggio, Paul J., and Walter W. Powell. 1983. "The Iron Cage Revisited: Institutional Isomorphism and Collective Rationality in Organizational Fields." American Sociological Review 48 (2): 147-16o.

Drori, Gili S., John W. Meyer, and Hokyu Hwang. 2006. Globalization and Organization: World Society and Organizational Change. Oxford: Oxford University Press.

Dunn, Kevin C. 2004. "Africa's Ambiguous Relation to Empire and Empire." In Empire's New Clothes: Reading Hardt and Negri, edited by Paul von Passavant and Jodi Dean, 143-64. New York: Routledge.

Eisenstadt, S.N. 2002. Multiple Modernities. New Brunswick, NJ: Transaction Publishers. Eriksen, Thomas Hylland. 1991. "Walls: Vanishing Boundaries of Social Anthropology." Trial lecture for Dr. Polit. degree, 14 September, http://folk.uio.no/geirthe/Walls .html.

Faist, Thomas, and Eyüp Özveren. 2004. Transnational Social Spaces: Agents, Networks, and Institutions. Aldershot, uk: Ashgate.

Fassin, Didier, and Mariella Pandolfi. 2010. Contemporary States of Emergency: The Politics of Military and Humanitarian Interventions. New York: Zone Books. 
Ferguson, James. 2006. Global Shadows: Africa in the Neoliberal World Order. Durham, NC: Duke University Press.

Finnemore, Martha, and Kathryn Sikkink. 1998. "International Norm Dynamics and Political Change." International Organization $5^{2}$ (4): 887-917.

Frobenius, Leo. 1898. Der westafrikanische Kulturkreis. Gotha: Justus Perthes.

Geertz, Clifford. 1973. "Religion as Cultural System." In The Interpretation Of Cultures: Selected Essays, 87-125. New York: Basic Books.

Gertel, Jörg. 2007. "Mobility and Insecurity: The Significance of Resources." In Pastoral Morocco, Globalizing Scapes of Mobility and Insecurity, edited by Jörg Gertel and Ingo Breuer, 11-30. Wiesbaden: Dr. Ludwig Reichert Verlag.

Glaser, Barney G., and Anselm L. Strauss. 1967. The Discovery of Grounded Theory: Strategies for Qualitative Research. Chicago, IL: Aldine.

Glick Schiller, Nina, Linda Basch, and Cristina Blanc-Szanton. 1992. "Transnationalism: A New Analytic Framework for Understanding Migration." In Towards a Transnational Perspective on Migration: Race, Class, Ethnicity, and Nationalism Reconsidered, edited by Glick Schiller, Nina, Linda Basch and Cristina Blanc-Szanton, 1-24. New York: New York Academy of Science.

Graebner, Fritz. 1911. Methode der Ethnologie. Heidelberg: Winter.

Green, Donals P., and Ian Shapiro. 1994. Pathologies of Rational Choice Theory: A Critique of Applications in Political Science. New Haven, Ст: Yale University Press.

Guyer, Jane I. 2002. "Briefing: The Chad-Cameroon Petroleum and Pipeline Development Project." African Affairs 101: 109-115.

Haraway, Donna Jeanne. 1991. "Situated Knowledges: The Science Question in Feminism and the Privilege of Partial Perspective." In Simians, Cyborgs, and Women: The Reinvention of Nature, edited by Donna Jeanne von Haraway, 183-202. New York: Routledge.

Hardt, Michael, and Antonio Negri. 200o. Empire. Cambridge, MA: Harvard University Press.

Hoinathy, Remadji. 2008. "Pétrole and Changement Sociale: le Cas du Canton Béro." Unpublished Working Paper for CRASH, N'Djamena, Chad.

Hoinathy, Remadji. 2012. "Pétrole et Changement Sociale. Rente Pétrolière, Dé-Agriculturation et Monétisation des Interactions Sociales dans le Canton Béro au Sud du Tchad." PhD diss., Martin Luther University of Halle-Wittenberg.

Huntington, Samuel P. 1968. Political Order in Changing Societies. New Haven: Yale University Press.

Jasanoff, Sheila, ed. 2004. States of Knowledge: The Co-production of Science and Social Order. London: Routledge.

Kalthoff, Herbert. 2008. "Einleitung: Zur Dialektik qualitativer Forschung und soziologischer Theoriebildung." In Theoretische Empirie: zur Relevanz qualitativer 
Forschung, edited by Herbert Kalthoff, Stefan Hirschauer and Gesa Lindemann, 8-35. Frankfurt am Main: Suhrkamp.

Kaufmann, Matthias, and Richard Rottenburg. 2012. "Translation als Grundoperation bei der Wanderung von Ideen." In Kultureller und sprachlicher Wandel von Wertbegriffen in Europa. Interdisziplinäre Perspektiven, edited by Rosemarie Lühr, Natalia Mull, Jörg Oberthür and Hartmut Rosa, 219-232. Frankfurt am Main: Peter Lang.

Kroeber, Alfred L. 1940. "Stimulus-Diffusion." American Anthropologist 40: 1-20.

Kroeber, Alfred L. 1964. "Diffusionism." In Social Change: Sources, Patterns and Consequences, edited by Amitai Etzioni and Eva Etzioni, 142-45. New York: Basic Books.

Latour, Bruno. 1986. The powers of association. In Power, action and belief. A new sociology of knowledge?, edited by Law, John, 264-28o. London: Routledge \& Kegan Paul.

Latour, Bruno. 1999. Pandora's Hope: Essays on the Reality of Science Studies. Cambridge, MA: Harvard University Press.

Latour, Bruno. 2005. Reassembling the Social: An Introduction to Actor-Network-Theory. Clarendon Lectures in Management Studies. Oxford: Oxford University Press.

Law, John, and Annemarie Mol. 2002. Complexities: Social Studies of Knowledge Practices. Durham, NC: Duke University Press.

Law, John. 1992. "Notes on the Theory of the Actor-Network: Ordering, Strategy, and Heterogeneity." Systemic Practice and Action Research 5 (4): 379-93.

Lewis, David, and David Mosse. 2006. Development Brokers and Translators: The Ethnography of Aid and Agencies. Bloomfield, ст: Kumarian Press.

Lipset, Seymour Martin. 1959. Some Social Requisites of Democracy: Economic Development and Political Legitimacy. American Political Science Review. 53: 69-105

Macamo, Elisio, and Dieter Neubert. 2008. "The New and its Temptations: Products of Modernity and their Impact on Social Change in Africa." In Unpacking the New: Critical Perspectives on Cultural Synchretization in Africa and Beyond, edited by Afe Adogame, Magnus Echtler and Ulf Vierke, 271-304. Vienna: LIT Verlag.

Mamdani, Mahmood. 2001. When Victims Become Killers: Colonialism, Nativism, and the Genocide in Rwanda. Princeton, NJ: Princeton University Press.

Marcus, George E. 1995. "Ethnography in/of the World System: The Emergence of Multi-Sited Ethnography." Annual Review of Anthropology 24: 95-117.

Mehler, Andreas. 2005. "Area Studies, the Analysis of Conflicts and the Evaluation of Preventive Practice in Africa." In Is Violence Inevitable in Africa? Theories of Conflict and Approaches to Conflict Prevention, edited by Ulf von Engel, Annamaria Gentili and Patrick Chabal, 99-126. Leiden: Brill.

Merry, S.E. 2006. "Transnational Human Rights and Local Activism: Mapping the Middle." American Anthropologist 108 (1): 38-51. 
Merton, Robert King. 1968. Social Theory and Social Structure. New York: Free Press.

Meyer, John W., Gili S. Drori, and Hokyu Hwang. 2006. "World Society and the Proliferation of Formal Organization." In Globalization and Organization: World Society and Organizational Change, edited by Gili S. Drori, John W. Meyer and Hokyu Hwang, 25-49. Oxford: Oxford University Press.

Mitchell, Timothy. 2002. Rule of Experts: Egypt, Techno-politics, Modernity. Berkeley: University of California Press.

Mol, Annemarie, and John Law. 1994. "Regions, Networks, and Fluids: Anemia and Social Topology." Social Studies of Science 24: 641-71.

Mosse, David. 2008. "International Policy, Development Expertise, and Anthropology." Focaal 52: 119-26.

Niewöhner, Jörg, and Thomas Scheffer. 2010. “Thickening Comparison: On the Multiple Facets of Comparability." In Thick Comparison:Reviving the Ethnographic Aspiration, edited by Thomas von Scheffer and Jörg Niewöhner, 1-16. Leiden: Brill.

Ong, Aihwa, and Stephen J. Collier. 2005. "Global Assemblages: Technology, Politics, and Ethics as Anthropological Problems." In Global Assemblages: Technology, Politics, and Ethics as Anthropological Problems, edited by Aihwa Ong and Stephen J. Collier, 1-21. Malden, MA: Blackwell Publishing.

Peck, Jamie, and Nik Theodore. 2010. "Mobilizing Policy: Models, Methods, and Mutations." Geoforum 41: 169-74.

Pegg, Scott. 2005. "Can Policy Intervention Beat the Resource curse? Evidence from the Chad-Cameroon Pipeline Project." African Affairs 105 (418): 1-25.

Pegg, Scott. 2009. "Briefing: Chronicle of a Death Foretold: The Collapse of the ChadCameroon Pipeline Project.” African Affairs 108 (431): 311-20.

Petermann, Werner. 2004. Die Geschichte der Ethnologie. Wuppertal: Hammer Verlag. Pries, Ludger. 1999. Migration and Transnational Social Spaces. Aldershot, uK: Ashgate. Reyna, Stephen. 2009. “Taking Place: 'New Wars' versus Global Wars.” Social Anthropology 17 (3): 291-317.

Richards, Paul. 1996. Fighting for the Rain Forest: War, Youth and Resources in Sierra Leone. Portsmouth, NH: Heinemann.

Robertson, Roland. 1992. Globalization: Social Theory and Global Culture. London: Sage. Ross, Michael. 2003. "Natural Resources and Civil War: An Overview". World Bank Research Observer.

Rostow, Walt. 1960/1990. The Stages of Economic Growth. A Non-Communist Manifesto. Cambridge: Cambridge University Press.

Rottenburg, Richard. 2002. Weit hergeholte Fakten: eine Parabel der Entwicklungshilfe. Stuttgart: Lucius and Lucius.

Rottenburg, Richard. 2005. "Code Switching, or Why a Metacode is Good to Have." In Global Ideas: How Ideas, Objects and Practices Travel in the Global Economy, edited 
by Barbara Czarniawska and Guje Sevón, 259-74. Copenhagen: Copenhagen Business School Press.

Rottenburg, Richard. 2009a.Far-Fetched Facts: a Parable of Development Aid. Cambridge, MA: The MIT Press.

Rottenburg, Richard. 2009b. "Social and Public Experiments and New Figurations of Science and Politics in Postcolonial Africa." Postcolonial Studies 12 (4): 423-40.

Rottenburg, Richard. 2013. "Ethnologie und Kritik." In Ethnologie im 21. Jahrhunder. Ethnologische Paperbacks, edited by Thomas Bierschenk, Matthias Krings and Carola Lentz, 55-76. Berlin: Reimer-Verlag.

Sarfaty, Galit A. 2012. Values in Translation: Human Rights and the Culture of the World Bank. Stanford, CA: Stanford University Press.

Schäbler, Birgit. 2007. "Das Studium der Weltregionen (Area Studies) zwischen Fachdisziplin und der Öffnung zum Globalen: Eine wissenschaftsgeschichtliche Annäherung." In Area Studies und die Welt: Weltregionen und neue Globalgeschichte, edited by Birgit von Schäbler, 11-44. Vienna: Mandelbaum-Verlag.

Schmidt, Wilhelm. 1926. Die Sprachfamilien und Sprachenkreise der Erde. Heidelberg: Winter.

Schumpeter, Joseph Alois 1942. Capitalism, Socialism, and Democracy. New York, London: Harper and Brothers.

Smith, G. Elliot, Bronislaw Malinowski, Herbert Joseph Spinden, and Alexander Goldenweiser. 1927. Culture: The Diffusion Controversy. New York: W.W. Norton.

Spittler, Gerd. 2003. "Globale Waren -Lokale Aneignungen." In Ethnologie der Globalisierung. Perspektiven kultureller Verpflechtung, edited by Brigitta Hauser-Schäublin and Ulrich Braukämper, 15-31. Berlin: Dietrich Reimer Verlag.

Szanton, David L. 2004. "Introduction: The Origin, Nature, and Challenges of Area Studies in the United States." In The Politics of Knowledge: Area Studies and the Disciplines, edited by David L. von Szanton, 1-33. Berkeley: University of California Press.

Thompson, Lena. n.d. "Gender Mainstreaming and Contested Practices in Sierra Leone." Unpublished Manuscript. Fourah Bay College, Freetown, Sierra Leone.

Tilley, Helen. 2011. Africa as a Living Laboratory: Empire, Development, and the Problem of Scientific Knowledge, 1870-1950. Chicago: University of Chicago Press.

Tomlinson, John. 1999. Globalization and Culture. Chicago: University of Chicago Press.

Tylor, Edward Burnett. 1888. "On a Method of Investigating the Development of Institutions, Applied to Laws of Marriage and Descent." Journalof the Anthropological Institute 18: 245-72.

von Trotha, Trutz. 2000. "Die Zukunft liegt in Afrika. Vom Zerfall des Staates, von der Vorherrschaft der konzentrischen Ordnung und vom Aufstieg der Parastaatlichkeit.” Leviathan 2: 253-79. 
Weber, Max. 2001. The Protestant Ethic and the Spirit of Capitalism. Translated by Talcott Parsons. London: Routledge.

Weszkalnys, Gisa. 2008. "Hope and Oil: An Ethnographic Study of the Emergent Oil Operations in São Tomé and Príncipe." Research Report, University of Exeter.

Weszkalnys, Gisa. 2009. "The Curse of Oil in the Gulf of Guinea: A View from São Tomé and Príncipe." African Affairs, Advance Access 108 (433: 1-11). 